\title{
REVIEW
}

\section{Molecular aspects of multiple myeloma}

\section{G Pratt}

J Clin Pathol: Mol Pathol 2002;55:273-283

Multiple myeloma is a malignant tumour of plasma cells with a median survival of two to three years. Karyotypic instability is seen at the earliest stage of the disease and increases with disease progression, leading to extreme genetic abnormalities similar to solid tumours. Translocations involving the immunoglobulin heavy chain region on chromosome $14 \mathrm{q} 32$ are clearly important in the pathogenesis of most myelomas. This review focuses on the different genetic abnormalities found in myeloma and discusses possible pathogenetic mechanisms and the implications for biologically based treatments.

Correspondence to: Dr G Pratt, Department of Haematology, Birmingham Heartlands Hospital, Bordesley Green East, Birmingham B9 5SS, UK; prattg@heartsol.wmids.nhs.uk

Accepted for publication 11 June 2002
M ultiple myeloma is a malignant neoplasm of plasma cells, which remains incurable with conventional chemotherapy, with a median survival between two and three years. It is only with the development of fluorescence in situ hybridisation (FISH) based techniques that the extent of cytogenetic abnormalities in myeloma cells has become apparent. ${ }^{1}$ Karyotypic instability is an early event in myeloma development and is a feature of patients with monoclonal gammopathy of uncertain significance (MGUS), ${ }^{2-4}$ a premalignant condition that may progress to myeloma. With disease progression myeloma is characterised by increasing and often extreme genetic abnormalities akin to solid tumours.

\section{MULTIPLE MYELOMA IS SEEN AS A} MULTISTEP TRANSFORMATION PROCESS

Although not discernible in every patient there is clearly a stepwise progression in myeloma. ${ }^{5}$ The initial event is the immortalisation of a plasma cell to form a clone, which may be quiescent, non-accumulating, and not causing end organ damage (MGUS). Transformation to myeloma may then occur, with plasma cells accumulating within the bone marrow (intramedullary myeloma), leading to end organ damage. The disease is usually chemosensitive and frequently enters a quiescent phase of variable duration (plateau phase). Finally, myeloma is characterised by drug resistance, resistance to apoptosis, and independence from growth factors and the bone marrow microenvironment (extramedullary myeloma). Occasionally at this stage cells may be propagated in vitro as myeloma cell lines. The understanding of genetic events in relation to these stages is k clearly crucial to understanding the pathogenesis of this disease. Most data relate to progressive disease, with little known about the immortalising and initial transforming events.

\section{LIMITATIONS OF CONVENTIONAL CYTOGENETICS IN MULTIPLE MYELOMA}

Conventional cytogenetic analysis in myeloma is difficult because of the low proliferation rate of malignant plasma cells, together with a variable degree of bone marrow infiltration, and this type of analysis grossly underestimates karyotypic changes in multiple myeloma. Using conventional karyotyping, clonal abnormalities are found in about $40 \%$ of cases overall and only $20-35 \%$ at diagnosis. ${ }^{6-13}$ The frequency and extent of karyotypic abnormalities correlates with the disease stage, duration, and response to treatment, with approximately $20 \%$ of patients with stage 1 disease having an abnormal karyotype, $60 \%$ in stage III, and $>80 \%$ with an extramedullary tumour. ${ }^{5}$ Therefore, most chromosomal changes described by conventional cytogenetics relate to either stage III disease or to relapsing disease and are not clearly associated with the emergence of the disease. When only normal metaphases are identified, it has been shown that they originate from the normal haemopoietic component. ${ }^{8}$ Culture parameters, particularly cytokines such as interleukin 6 (IL-6) and granulocyte colony stimulating factor, and length of culture, may improve the number of cases with abnormal cytogenetics. ${ }^{11} 1415$

\section{"The frequency and extent of karyotypic abnormalities correlates with the disease stage, duration, and response to treatment"}

In most instances, the abnormal karyotypes generally show numerous structural abnormalities, together with a numerical abnormality, and some patients have multiple abnormal clones. However 9-11\% of karyotypes show structural changes as the sole abnormality. ${ }^{19}$ It is clear that

Abbreviations: CDK, cyclin dependent kinase; $\mathrm{CGH}$, comparative genomic hybridisation; $E$, enhancer sequence; Fas-L, Fas ligand; FGF, fibroblast growth factor; FGF3R, fibroblast growth factor 3 receptor; FISH, fluorescence in situ hybridisation; HGF, hepatocyte growth factor; IGF, insulin growth factor; lgH, immunoglobulin heavy chain; IL, interleukin; IL-6R, interferon 6 receptor; IRF, interferon regulatory factor; MAPK, mitogen activated protein kinase; MGUS, monoclonal gammopathy of uncertain significance; myeov, myeloma overexpressed gene; $O P G$, osteoprotegerin; $p R b$, retinoblastoma protein; $\mathrm{RANKL}$, receptor activator of nuclear factor $\kappa \mathrm{B} ; \mathrm{Rb}$, retinoblastoma gene; RT-PCR, reverse transcription polymerase chain reaction; S, switch sequence; SKY, multicolour spectral karyotyping; STAT, signal transducer and activator of transcription; TACC3, transforming acidic coiled coil containing gene; TGF- $\beta$, transforming growth factor $\beta$; TNF- $\alpha$, tumour necrosis factor $\alpha$; VEGF, vascular endothelial growth factor 
no single pattern occurs. Karyotypically abnormal patients are more likely to be hyperdiploid (approximately 46-68\%) rather than pseudodiploid or hypodiploid. ${ }^{6-811} 1216$ The main numerical and structural abnormalities that have been reported in myeloma using conventional cytogenetics are gains of chromosomes 9q, 3, 12q, 19, 15q, 11q, 7, 5, 17q, 18, 21, and 22q (trisomy or tetrasomy), loss of 13q, X (females), 14, 6q, 8, 16, and $\mathrm{Y}$ (monosomy or nullosomy), and structural changes involving $14 q+, 16 p$ or $16 q$, lp or $1 \mathrm{q}$ (partial deletion, trisomy 1q), 11q13, 19q13 or 19p13, 6q, 17q, 2pl2 or 22q11, and 7q.

\section{ALMOST ALL PATIENTS WITH MYELOMA HAVE CYTOGENETICALLY ABNORMAL TUMOUR CELLS}

With the advent of newer molecular techniques it is now clear that $95-100 \%$ of patients with multiple myeloma show abnormal karyotypes, usually with highly complex changes, involving both structural and numerical abnormalities. ${ }^{1}$ In particular, the prognostic importance of deletions of $13 q$ and the frequency of $14 \mathrm{q} 32$ translocations in myeloma have only become apparent over the past few years. Initial evidence for the karyotypic instability in myeloma came from flow cytometric analysis of DNA content, which demonstrated aneuploidy in up to $80 \%$ of patients with multiple myeloma. ${ }^{17} 18$ This was confirmed more recently with the advent of FISH analysis, with aneuploidy being found in more than $89 \%$ to $96 \%$ of cases. ${ }^{19-21}$ Using FISH, $61-66 \%$ of patients show hyperdiploidy, 9-20\% pseudodiploidy, and 10-30\% hypodiploidy. Interphase FISH has also demonstrated clonal karyotypic abnormalities in over $50 \%$ of patients with MGUS, indicating that karyotypic changes are an early event. ${ }^{2-4}$ Using FISH in myeloma, abnormalities of four or more chromosomes are detected in $80 \%$ of cases, with $10 \%$ of cases having abnormalities of more than 20 chromosomes. ${ }^{22}$ Trisomies appear to occur more commonly than monosomies: trisomy of chromosomes 3, 5, 7, 9, 11, 15, and 19 and monosomy of chromosomes $6,8,13,14$, and $X$ are the most commonly reported numerical abnormalities. Structural abnormalities are equally common and affect principally chromosomes 1, 6, 11, and 14. It has been suggested recently that the use of three centromeric probes for chromosomes 1, 9, and 13 or 1, 9, and 15 will detect all cases with an abnormal karyotype (JF San Miguel et al. Presented at the Proceedings of the Vth International Workshop on Multiple Myeloma 1995.

\section{"The true frequency and spectrum of chromosomal changes in myeloma and their correlation with prognostic indicators requires larger studies and more sophisticated techniques to identify all the karyotypic abnormalities"}

Comparative genomic hybridisation (CGH) is a method of examining numerical chromosome changes based upon quantitation of the fluorescence intensity of differentially labelled normal and tumour DNA hybridised to normal metaphase chromosomes. Regions of sequence loss and gain approximating $10 \mathrm{Mb}$ are visible, although balanced translocations are not detected using CGH. Using this technique, Avet-Loiseau et al found that the loss of sequences on 13q and $14 \mathrm{q}$ and the gain of sequences on $\mathrm{lq}$ and chromosome 7 occurred in $50-60 \%$ of patients with multiple myeloma, with hot spots of sequence loss at 13q12.1-21, 13q32-34, 14q11.213 , and $14 \mathrm{q} 23-31 . .^{23}$ Using this approach, Cigudosa et al suggested that the most frequent events are gains of chromosome 19 or $19 \mathrm{p}$ and complete or partial deletions of $13 .{ }^{24}$ Other recurrent changes included gains of $9 q, 11 q, 12 q, 15 q, 17 q$, and $22 \mathrm{q}$ and losses of $6 \mathrm{q}$ and 16q. Using CGH the regions of chromosome 6 and 13 have been narrowed down to $6 \mathrm{q} 21$ and 13q14-21.

Recently, newer FISH based techniques termed multicolour spectral karyotyping (SKY) and multicolour FISH have been described which enable the precise identification of complex chromosomal rearrangements. SKY is a molecular cytogenetic technique that allows the simultaneous display of each chromosome in a different colour, making it possible to identify chromosomal bands of unknown origin. However, it is limited by the need for metaphases and the inability to detect inversions, very small deletions, insertions, or translocations of less than $500 \mathrm{~kb}$.

Rao et al, ${ }^{25}$ using SKY, identified several new recurring sites of breakage that mapped to the chromosomal bands 3q27, 17q24-25, and 20q11. Two new translocations involving 14q32 were identified in cell lines, namely: $\mathrm{t}(12 ; 14)(\mathrm{q} 24 ; \mathrm{q} 32)$ in XG2 cells and $\mathrm{t}(14 ; 20)(\mathrm{q} 32 ; \mathrm{ql})$ in SKMMl cells. Sawyer et al applied SKY to 50 bone marrow samples from patients with myeloma and identified the $\mathrm{t}(14 ; 16)(\mathrm{q} 32 ; \mathrm{q} 22-23)$ translocation in six patients and $t(9 ; 14)(\mathrm{pl} 3 ; \mathrm{q} 32)$ in two patients. ${ }^{26}$ Eight cases demonstrated loss of $8 \mathrm{p}$, suggesting the loss of a putative tumour suppressor gene on $8 \mathrm{p}$.

It is clear that resolving the complex karyotypes of multiple myeloma requires the application of multiple techniques, including both FISH and SKY, and even then subtle events are unlikely to be resolved. The true frequency and spectrum of chromosomal changes in myeloma and their correlation with prognostic indicators requires larger studies and more sophisticated techniques to identify all the karyotypic abnormalities.

\section{THE IMPORTANCE OF TRANSLOCATIONS INVOLVING CHROMOSOME 14Q32 IN MULTIPLE MYELOMA AS AN EARLY EVENT IN MYELOMA PATHOGENESIS}

Chromosome 14q32 translocations (immunoglobulin heavy chain $(\mathrm{IgH})$ translocations) in multiple myeloma are probably important early events in its pathogenesis. ${ }^{27}$ Although there are several recurrent translocation partners identified a promiscuous range of non-recurrent partner chromosomes has also been described. Several of these $14 \mathrm{q}$ translocations are not detected by conventional cytogenetics because of the telomeric positions of the loci involved. They occur in most patients, with an incidence of $60-65 \%$ in intramedullary myeloma, $70-80 \%$ in extramedullary myeloma, and $>90 \%$ in myeloma cell lines. ${ }^{27}$ Chromosomal translocations affecting the transcriptionally active $\mathrm{IgH}$ locus on $14 \mathrm{q} 32$ are the hallmark of B cell malignancies. They represent the mechanism of activation of several proto-oncogenes in B cell lymphoid neoplasms ${ }^{28}$ such as Burkitt's lymphoma, follicular lymphoma, and mantle cell lymphoma. They are probably an early event in myeloma development because they occur during physiological class switch recombination or uncommonly during somatic hypermutation, both of which occur in the lymphoid germinal centre in germinal centre B cells. These translocations are usually reciprocal translocations with no heterogeneity within the myeloma clone. Bergsagel and Kuehl ${ }^{29}$ have contrasted IgH translocations with other secondary translocations in myeloma. Secondary translocations occur late in the disease, are usually complex, involve mechanisms other than aberrant class switch recombination or somatic hypermutation, and are less often IgH associated.

The incidence of IgH translocations in MGUS is $50 \%$, which also suggests that they are an early event. ${ }^{4}$ The high incidence of these translocations in patients with MGUS suggests that they may not be sufficient to transform the clone to myeloma. Consistent with this notion, B cells that carry chromosomal translocations involving the $\mathrm{IgH}$ loci-namely bcl-2 and c-myc — can be found in normal humans, suggesting that IgH translocations alone may not be sufficient to render a B cell malignant. ${ }^{29}$ The incidence of $\mathrm{IgH}$ translocations increases with disease progression, indicating that they also occur later in the disease process.

Bersagel's group was the first to highlight the high frequency of $14 \mathrm{q} 32$ translocations using a Southern blot 

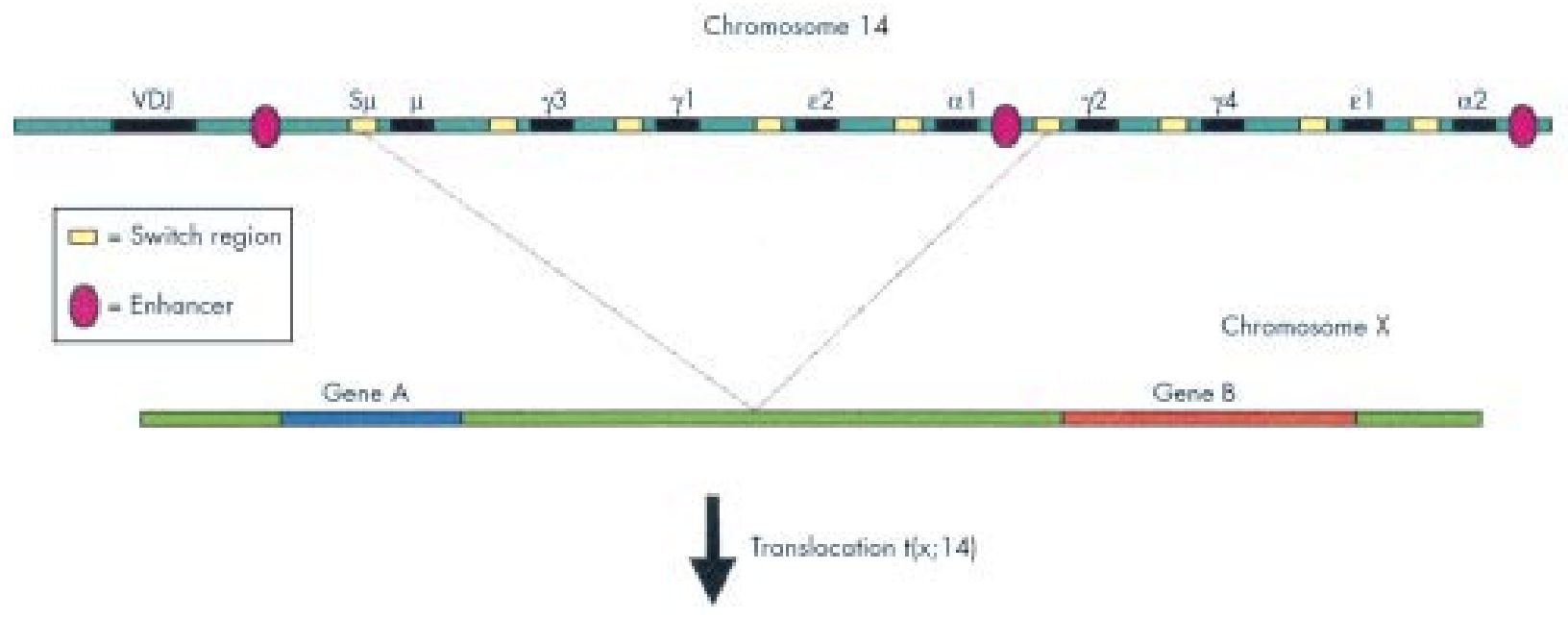

Derivative $\mathrm{X}$ chromosome
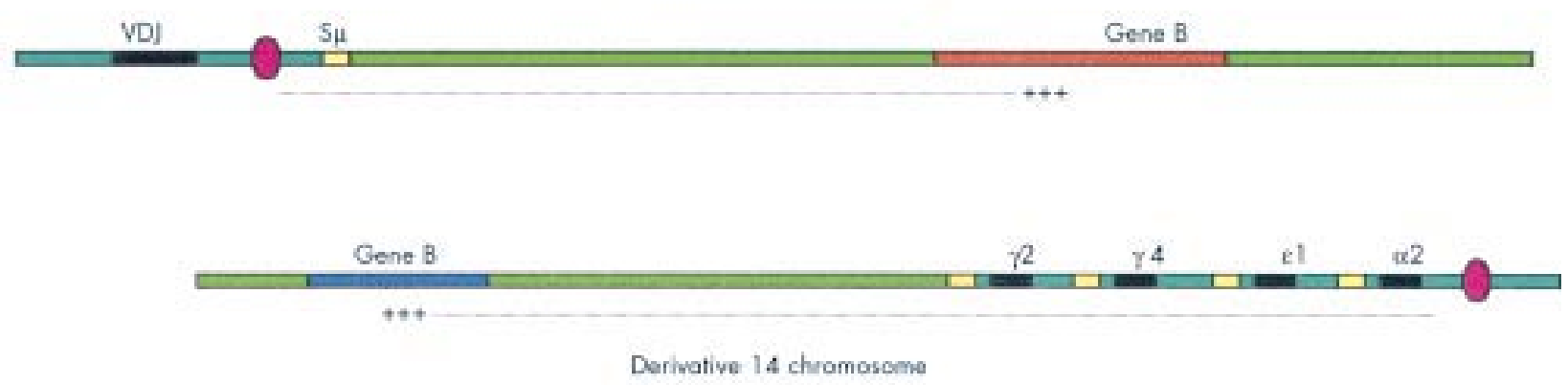

Figure 1 Chromosome $14 q 32$ translocations in multiple myeloma. Breakpoints occur in two switch regions on $14 q 32$ with loss of the intervening $14 \mathrm{q} 32$ sequence. Enhancers are present on both derivative chromosomes and can lead to dysregulation of genes on both derivative chromosomes.

assay $^{30}$ and this group has subsequently characterised the most common recurrent translocations at the molecular level. ${ }^{27}$ This technique was mainly applied to myeloma cell lines, although small numbers of primary tumours were also analysed. They have now identified at least one IgH translocation in 36 of 39 myeloma cell lines, with at least 17 of 39 having two or more different IgH translocations. ${ }^{27}$ The three cell lines without $\operatorname{IgH}$ translocations all had $\operatorname{Ig} \lambda$ translocations, presumably as a result of somatic hypermutation. ${ }^{27}$

Chromosome 14q32 translocations are also found in a large proportion of patients using FISH based studies (for example, $71 \%,{ }^{31} 57 \%,{ }^{32} 47 \%,{ }^{33}$ and $\left.68 \%{ }^{34}\right)$. Using a Southern blot assay similar to Bergsagel, Ho et al found that 12 of 21 patients had $14 \mathrm{q} 32$ translocations. ${ }^{35}$ Using FISH analysis, $14 \mathrm{q} 32$ translocations were not detected in every patient with multiple myeloma; about a third of patients had no detectable karyotypic abnormality involving the IgH loci. ${ }^{31}{ }^{34}$ In a minority of patients with $14 \mathrm{q} 32$ translocations, FISH studies are unable to show a reciprocal translocation, indicating that the $14 \mathrm{q} 32$ translocation may not be reciprocal in all patients.

The promiscuous number of partners involved in translocations to the Ig locus at $14 \mathrm{q} 32$ has also been demonstrated and extended by FISH and SKY studies. ${ }^{25} 211$ Thus far, more than 20 different chromosomal partner regions translocating to $14 q 32$ have been reported in patients with multiple myeloma, and only a few have been found as recurrent rearrangements. Recurrent translocations include $\mathrm{t}(11 ; 14)(\mathrm{q} 13 ; \mathrm{q} 32)$, $\mathrm{t}(4 ; 14)(\mathrm{pl} 6 ; \mathrm{q} 32), \mathrm{t}(6 ; 14)(\mathrm{p} 25 ; \mathrm{q} 32), \mathrm{t}(6 ; 14)(\mathrm{p} 21 ; \mathrm{q} 32)$, and $\mathrm{t}(14 ; 16)(\mathrm{q} 32 ; \mathrm{q} 23)$. Rare but recurrent translocations also include $\mathrm{t}(8 ; 14)(\mathrm{q} 24 ; \mathrm{q} 32)$ and $\mathrm{t}(14 ; 18)(\mathrm{q} 32 ; \mathrm{q} 21)$.
The anatomy of IgH translocations in multiple myeloma is interesting (fig 1). There are at least three enhancers present on IgH that regulate transcription in B cells; the intronic enhancer $(\mathrm{E} \mu)$ located in the intron between the $\mathrm{JH}$ and switch $\mu$ (S $\mu$ ) sequences and two powerful 3' IgH enhancers located downstream of the $\alpha$ constant region genes ( $E \alpha l$ and E $\alpha 2$ ). In mantle cell lymphoma and follicular lymphoma the breakpoints in IgH translocations occur into the VDJ region. In contrast, in multiple myeloma the breakpoints usually occur into switch regions (occasionally into the JH region), which are non-coding, highly repetitive sequences located 5' of the constant region genes and are involved in class switch recombination. Switch region breakpoints are also found in the $t(8 ; 14)$ translocation in sporadic Burkitt's lymphoma, the rare $t(14 ; 19)$ in chronic lymphocytic leukaemia, and the $\mathrm{t}(3 ; 14)$ and $\mathrm{t}(10 ; 14)$ translocations found in diffuse large cell lymphoma. As a result of a reciprocal translocation into a switch region these enhancers are split on to each derivative chromosome and can therefore potentially dysregulate oncogenes on both chromosomes. This is true for the two most common recurrent translocations, the $\mathrm{t}(11 ; 14)$ (oncogenes dysregulated: cyclin Dl on der(14) and myeov (myeloma overexpressed gene) on $\operatorname{der}(11))$ and $t(4 ; 14)$ (oncogenes dysregulated: FGFR3 (encodes fibroblast growth factor 3 receptor) on $\operatorname{der}(14)$ and MMSET on $\operatorname{der}(4))$.

We and others have cloned IgH breakpoints in patients with multiple myeloma and most commonly these translocations involve three DNA breaks, with two breaks on the IgH locus and one on the reciprocal chromosome (fig l) (JAL Fenton et al, unpublished data, 2002). ${ }^{27}$ The $5^{\prime}$ breakpoints in the $\operatorname{IgH}$ 
locus most commonly occur in or $5^{\prime}$ of $S \mu$, with a $3^{\prime}$ breakpoint in a downstream switch region, usually an $S \gamma$ or $S \alpha$. In normal class switch recombination, such breaks occur in $S \mu$ and a downstream switch region, with looping out of intervening DNA and the formation of a hybrid switch region so that a new heavy chain gene is juxtaposed to the VDJ region. In myeloma, there is a failure to join these switch regions, although intervening DNA is looped out, and the switch regions are instead joined to other available chromosome ends (fig 1). This indicates that these translocations occur during class switch recombination.

"B cells that carry chromosomal translocations involving the $\mathrm{lgH}$ loci can be found in normal humans, suggesting that $\mathrm{lgH}$ translocations alone may not be sufficient to render a B cell malignant"

Recently, an insertional event has been shown in the U266 myeloma cell line ${ }^{37}$ where a portion of excised IgH switch intervening sequences containing the $3^{\prime} \alpha$ - 1 enhancer, formed during an IgH $\mu$ to $\epsilon$ switch recombination, is inserted into chromosome 1lq13, resulting in overexpression of the adjacent cyclin Dl oncogene. We have also identified an insertional event in a patient with myeloma, where a $132 \mathrm{bp}$ sequence of chromosome 22 is inserted into a region $5^{\prime}$ of $\mathrm{S} \mu^{38}$ in addition to several deletional events in patients with multiple myeloma (JAL Fenton et al, unpublished data, 2002). These events underline the instability of switch regions in multiple myeloma and suggest that dysregulation of genes may occur by insertional and deletional events in addition to translocations.

Despite the evidence for IgH translocations being important in the pathogenesis of myeloma there remain several unanswered questions. ${ }^{27}$ It is not clear why there is an apparent promiscuity of partner chromosomes involved in $\mathrm{IgH}$ translocations or whether the IgH enhancers may have properties of a locus control region and are dysregulating other as yet unidentified genes. In addition, the effect of these translocations on plasma cell biology in terms of apoptosis, proliferation, and differentiation are unclear, as is the role they play in the development of MGUS and the establishment of myeloma. Data are emerging as to the prognostic relevance of chromosome 14 translocations. The $\mathrm{t}(4 ; 14)$ appears to be associated with a poorer prognosis, ${ }^{39}$ whereas the $\mathrm{t}(11 ; 14)^{40}$ translocation does not appear to be associated with a worse prognosis, as had previously been thought. Translocations involving the IgH locus are also common and are possibly early events in primary systemic amyloidosis. ${ }^{41}$

\section{RECURRENT 14Q32 TRANSLOCATIONS The $t(11 ; 14)(q 13 ; 32)$ translocation}

The $\mathrm{t}(11 ; 14)(\mathrm{q} 13 ; \mathrm{q} 32)$ translocation is the most common translocation in multiple myeloma, with a frequency of $15-20 \%$, and is detectable by FISH and conventional cytogenetics. ${ }^{11} 3242$ This translocation has recently been reported to be common in primary systemic amyloidosis. ${ }^{41}$ The translocation leads to dysregulation of cyclin Dl, which normally promotes the progression of the cell from the Gl growth arrest phase into the $\mathrm{S}$ phase, and is not normally expressed in plasma cells. The exact nature of this dysregulation has not been well characterised in terms of whether cyclin Dl is overexpressed continuously, with loss of cell cycle control, or whether there is an increase in the cyclic concentrations of cyclin Dl only. The $\mathrm{t}(11 ; 14)(\mathrm{q} 13 ; \mathrm{q} 32)$ translocation, with dysregulation of cyclin D1, is the hallmark of mantle cell lymphoma. ${ }^{43}$ However, the breakpoints differ from those seen in myeloma. In myeloma samples, the breakpoints in $1 \mathrm{lq} 13$ do not cluster and are scattered throughout the $360 \mathrm{~kb}$ region between the cyclin Dl gene and the myeov gene. ${ }^{44}$ In contrast, in mantle cell lymphoma there is clustering on 1lq13 within the major translocation cluster. The breakpoints in the IgH locus in multiple myeloma are usually inside switch regions or occasionally in the JH region, ${ }^{30}{ }^{45-49}$ in contrast to mantle cell lymphoma, where IgH breakpoints involve the VDJ region. A variant translocation involving a light chain gene has been described in myeloma. ${ }^{50} \mathrm{~A}$ translocation breakpoint has also been found within the 3' untranslated region of cyclin Dl, resulting in a $3^{\prime}$ truncated mRNA. ${ }^{46}$ Dysregulation of cyclin D1 has been shown to occur in the U266 myeloma cell line by an insertional event. In this cell line a portion of excised IgH switch intervening sequence containing the $3^{\prime} \alpha$-1 enhancer has inserted into chromosome $11 \mathrm{q} 13 .{ }^{37}$

Because IgH enhancers are present on the der(11) chromosome there may be dysregulation of the myeov gene on the derll derivative chromosome. This gene was initially identified as an oncogene using DNA from a gastric carcinoma in a transformation assay and has no known homology to other proteins. It has been found to be upregulated in three of seven myeloma cell lines with 1 lq13 translocations. ${ }^{44}$

\section{"Patients with the $t(11 ; 14)$ translocation do not have a} worse prognosis as had previously been thought"

Initially, there were several groups reporting an association of $t(11 ; 14)$ with a poor prognosis ${ }^{10} 51$ and also circulating plasma cells. ${ }^{42}$ However, more recently larger studies have shown that patients with the $t(11 ; 14)$ translocation do not have a worse prognosis. Avet-Loiseau and colleagues ${ }^{32}$ identified the translocation using FISH in 16\% (23 of 141 patients) of patients with plasma cell malignancies, but found no correlation with stage, immunoglobulin subtype, or $\beta 2$ microglobulin values. More recently, Fonseca et al identified this translocation in 53 of 336 evaluable patients (16\%) and showed that these patients were more likely to have lymphoplasmacytic morphology, a small monoclonal paraprotein, and a lower plasma cell labelling index, but were less likely to be hyperdiploid. This study clearly showed that patients with the $\mathrm{t}(11 ; 14)$ translocation do not have a worse prognosis as had previously been thought.

\section{The $t(4 ; 14)(p 16.3 ; q 32.3)$ translocation}

The $\mathrm{t}(4 ; 14)(\mathrm{pl} 6.3 ; \mathrm{q} 32.3)$ is found in approximately $15 \%$ of patients with multiple myeloma using FISH based techniques $^{32} 52$ or reverse transcription polymerase chain reaction (RT-PCR). ${ }^{53}$ This translocation is undetectable by conventional karyotypic or spectral karyotypic analysis because of the telomeric location of the breakpoints on each chromosome. On chromosome 4pl6 the breakpoints occur within the $5^{\prime}$ exons of the MMSET gene, clustering within a region of about $60 \mathrm{~kb}^{54}$ This breakpoint clustering is not seen with the other recurrent $14 \mathrm{q} 32$ translocations in multiple myeloma. The $5^{\prime}$ exons of MMSET are largely non-coding, but truncated forms of the MMSET protein may occur if the breakpoints occur upstream of exon 4 or $5 .{ }^{54}$ On the der4 chromosome derivative of the translocation the MMSET gene becomes dysregulated because of the presence of the IgH intronic enhancer and, in addition, hybrid mRNA transcripts are formed between IgH ( $\mathrm{JH}$ and $\mathrm{I} \mu$ exons) and the MMSET gene on chromosome $4 .^{53}$ The hybrid transcripts provide an easy means of detecting this translocation using RT-PCR, although these transcripts are not thought to code for a fusion protein. The breakpoints on chromosome 4 occur $50-100 \mathrm{~kb}$ centromeric to the FGFR3 gene that becomes dysregulated on the der 14 chromosome derivative of the translocation as a result of the strong 3' IgH enhancers. ${ }^{55}$

MMSET encodes a nuclear protein that shares homology with other PHD and SET domain proteins, such as ASHI and trithorax in drosophila and the MLLl gene on chromosome 
11 q23 that is frequently dysregulated in acute leukaemias. ${ }^{54}$ It may be involved in chromatin remodelling, particularly in embryogenesis, and is a potential oncogene. Wolf-Hirschhorn syndrome is a multiple malformation syndrome associated with a germline hemizygous deletion of the distal short arm of chromosome 4 and it involves the loss of one allele of MMSET. ${ }^{56}$ MMSET is expressed preferentially in rapidly growing embryonic tissues, in a pattern corresponding to affected organs in patients with Wolf-Hirschhorn syndrome, and this gene is probably responsible for many of the phenotypic features of Wolf-Hirschhorn syndrome. ${ }^{56}$

\section{"Activated FGFR3 is clearly oncogenic, with an ability to transform fibroblasts and generate tumours in nude mice"}

FGFR3 is one of a family of five tyrosine kinase receptors for the fibroblast growth factor (FGF) family of ligands, which are expressed ubiquitously by cells of mesodermal origin. These receptors regulate a multitude of cellular processes and have been strongly implicated in tumorigenesis and angiogenesis. In particular, FGFR3 signalling can substitute for IL-6 for the growth and survival of an IL-6 dependent murine plasmacytoma cell line, with signalling through signal transducer and activator of transcription 3 (STAT3) and higher concentrations of bcl- $\mathrm{X}_{\mathrm{L}} \cdot{ }^{57}$ Activated FGFR3 is clearly oncogenic, with an ability to transform fibroblasts and generate tumours in nude mice. ${ }^{58}$ In a mouse transplant model, murine haemopoietic cells transfected with either wild-type or activated FGFR3 generate a pre-B cell leukaemia/lymphoma following transplantation into mice, within six weeks for activated FGFR3 and approximately one year after transplant for wild-type FGFR3. ${ }^{59}$

Germline activating mutations of FGFR are responsible for autosomal dominant disorders of skeletal and cranial development (including achondroplasia and thantophoric dysplasia). These mutations are usually a single amino acid change and lead to constitutive activation of the receptor in the absence of ligand. Identical activating mutations have been found often in bladder cancer and rarely in cervical cancer. In myeloma, these mutations appear to occur only rarely in patients with the $t(4 ; 14)$ translocation and are associated with disease progression, presumably by allowing growth factor independence..$^{58}{ }^{60}$ About a third of cell lines with the $t(4 ; 14)$ translocation have activating mutations involving FGFR3. Those that do not have activating FGFR3 mutations may have mutations of ras, but no cell lines with the $t(4 ; 14)$ translocation have been found to contain mutations of FGFR3 together with ras mutations, suggesting that activation of either FGFR3 or ras may provide similar downstream events to malignant plasma cells. ${ }^{58}$ It is clear that different signal transduction pathways may be induced by FGFR3 activation depending on the cell system investigated. Deregulated FGFR3 mutants in MM cell lines appear to activate mainly the mitogen activated protein kinase (MAPK) pathway, although it is possible that other pathways may be activated by FGFR3. ${ }^{58} 61$

Recently a novel gene, transforming acidic coiled coil containing gene (TACC 3 ), has been found adjacent to the FGFR3 gene. ${ }^{62}$ TACC3 is upregulated in various cancer cell lines and during embryonic development in mice, suggesting a role in the control of cell growth and differentiation. ${ }^{62}$ The proximity of TACC3 to FGFR3, and consequently to the breakpoints in the $t(4 ; 14)$ translocations, raises the possibility that this translocation may also dysregulate the expression of TACC3.

The clustering of breakpoints within the $5^{\prime}$ MMSET genes and the IgH switch regions suggests that dysregulation of both MMSET and FGFR3 may be important in the pathogenesis of this group of myelomas. ${ }^{27}$ Recently, two groups have shown a strong association of the $t(4 ; 14)$ translocation with chromo- some 13 abnormalities. ${ }^{3963}$ Avet-Loiseau et al found that the $\mathrm{t}(4 ; 14)$ was associated with a homogenous group of patients characterised by a high incidence of chromosome 13 abnormalities, a higher incidence of IgA subtype, and a poor prognosis. ${ }^{39}$ However, there was disagreement between these two studies regarding the incidence of $t(4 ; 14)$ in MGUS, with Avet-Loiseau and colleagues ${ }^{39}$ almost never finding this translocation in MGUS but Fonseca and colleagues ${ }^{63}$ finding it in five of 52 individuals with MGUS, a similar incidence to that seen in their myeloma series.

\section{The $t(14 ; 16)(q 32.3 ; q 23)$ translocation}

The $\mathrm{t}(14 ; 16)(\mathrm{q} 32.3 ; \mathrm{q} 23)$ translocation has been identified in $5-10 \%$ of patients with multiple myeloma and leads to dysregulation of the c-maf proto-oncogene. C-maf is a basic zipper transcription factor, a member of a large family of transcription factors involved in many basic cellular processes, including those involving IL-6, a cytokine with a central role in the pathogenesis of myeloma, and c-maf also acts as a $\mathrm{T}$ cell transcription factor. Its viral analogue v-maf is a classic oncogene identified in an avian transforming virus, ${ }^{64}$ and overexpression of wild-type c-maf is capable of contributing to the transformation of fibroblasts in a model system. ${ }^{65}$ The breakpoints identified on 16p23 occur over a region 550$1350 \mathrm{~kb}$ centromeric to c-maf, within the $800 \mathrm{~kb}$ intron of an oxidoreductase gene, WWOX/FOR. ${ }^{66}$ This region is a common fragile site and the translocation inactivates one allele of the WWOX/FOR gene. WWOX/FOR has been implicated as a tumour suppressor gene in several solid tumours. ${ }^{66}$

\section{"The classic translocations to $14 q 32$ described in Burkitt's lymphoma and follicular lymphoma are very rare events in myeloma"}

How c-maf contributes to the pathogenesis of myeloma tumours with $t(14 ; 16)$ is unknown. Despite the large distance between the IgH enhancers and c-maf it is clearly highly upregulated in tumours with this translocation, indicating the power of the IgH enhancers.

\section{The $t(6 ; 14)(p 21 ; q 32)$ translocation}

The dysregulation of cyclin D3 as a result of the translocation of $6 \mathrm{p} 21$ into a $\gamma$ switch sequence was recently described in a myeloma cell line. ${ }^{67}$ This translocation was subsequently identified in six of 150 patients (4\%) by metaphase chromosome analysis and three of 53 by microarray analysis for cyclin D3 expression, then confirmed by FISH. ${ }^{67}$ One tumour had a $\mathrm{t}(6 ; 22)(\mathrm{p} 2 \mathrm{l} ; \mathrm{q} 1 \mathrm{l})$ translocation. The overall frequency of translocations involving the cyclin D pathway (cyclin Dl in $15-20 \%$ and cyclin D3 in 5\%) in myeloma highlights the importance of this pathway.

\section{The $t(6 ; 14)(\mathrm{p} 25 ; \mathrm{q} 32)$ translocation}

Iida and colleagues ${ }^{68}$ found the $t(6 ; 14)(\mathrm{p} 25 ; \mathrm{q} 32)$ translocation in three of 17 myeloma cell lines, leading to juxtaposition of the heavy chain locus to the multiple myeloma oncogene 1 (MUM 1)/interferon regulatory factor 4 (IRF4) gene and overexpression of the protein, a member of the IRF family known to be active in the control of B cell proliferation and differentiation. IRF4 has oncogenic activity in vitro in transfected rat fibroblasts. The exact incidence of this translocation and its role in the pathogenesis of myeloma currently remain unclear.

\section{$\mathrm{T}(1 ; 14)(\mathrm{q} 21 ; \mathrm{q} 32)$ translocations}

Hatzivassiliou and colleagues ${ }^{69}$ identified two new genes adjacent to the breakpoint in the $t(1 ; 14)(\mathrm{q} 21 ; \mathrm{q} 32)$ translocation in the FR4 human plasmacytoma cell line. These two genes, termed IRTAl and IRTA2, were related to the Fc receptor family, important cell surface receptors in lymphocytes, and 
therefore theoretically potential oncogenes dysregulated by this translocation. From SKY analyses of 150 tumours, the incidence of $\mathrm{t}(4 ; 14)(\mathrm{q} 21 ; \mathrm{q} 32)$ translocation is about $1-2 \%$ in advanced myeloma tumours. ${ }^{70}$ The location of the breakpoints far outside of the switch region in the FR4 cell line suggests that these translocations may be late, secondary translocations, not involving switch recombination. Indeed, chromosome 1 aberrations, particularly of 1q21, are frequent in solid tumours and in myeloma, where they appear to be associated with disease progression.

\section{The $t(8 ; 14)(q 24 ; q 32), t(14 ; 18)(q 32 ; q 21)$, and $t(9 ; 14)(p 13 ; q 32)$ translocations in multiple myeloma}

These translocations, which involve the proto-oncogenes c-myc and bcl-2, play a crucial role in other B cell malignancies (c-myc, Burkitt's lymphoma; bcl-2, follicular non-Hodgkin's lymphoma). The classic translocations to $14 \mathrm{q} 32$ described in Burkitt's lymphoma and follicular lymphoma are very rare events in myeloma. However, these oncogenes are frequently dysregulated through other mechanisms. C-myc dysregulation has recently been found to occur through complex translocations occurring late in the disease process and not always involving the IgH locus. ${ }^{71} 72$ The $t(9 ; 14)(\mathrm{pl} 3 ; \mathrm{q} 32)$ translocation has also been found in rare patients with myeloma. ${ }^{2633}$ This translocation dysregulates the PAX-5 gene at $9 \mathrm{pl} 3$ and is usually associated with lymphoplasmacytoid lymphoma/ Waldenstrom's macroglobulinaemia. ${ }^{73}$

\section{IMPORTANCE OF DELETION 13Q14 AS AN ADVERSE PROGNOSTIC INDICATOR}

By conventional cytogenetics, monosomy 13 and deletion of $13 q$ have been detected in $15-20 \%$ of patients. Using interphase FISH with two probes the frequency of $13 q 14$ deletions was initially found to be up to $50 \% .^{74}{ }^{75}$ However, recently Shaughnessy and colleagues ${ }^{76}$ used 11 probes spanning the entire long arm of chromosome 13 and found that $86 \%$ of patients had chromosome 13 deletions. In addition, considerable deletion heterogeneity was noted, with cells with homozygous deletions, monosomy, and no deletions being found within individual patients. The presence of a 13q deletion as assessed by the initial FISH studies using two probes was associated with a short event free and overall survival after conventional or high dose treatment. ${ }^{75} 77$ Together, the $\beta 2$ microglobulin value and the $13 \mathrm{q}$ status provide the most powerful prognostic indicators. ${ }^{77}$

The high incidence of deletion detected using 11 probes by Shaughnessy ${ }^{76}$ poses a dilemma with regard to the adverse prognosis reported using FISH with two probes. ${ }^{75}$ Further work is necessary to determine which deleted regions confer the adverse prognosis in myeloma and to identify the important deleted gene or genes in these regions. Chromosome 13q deletions are also common in chronic lymphocytic leukaemia but do not confer an adverse prognosis. Monoallelic deletion of the retinoblastoma $(\mathrm{Rb})$ gene in this region is common in myeloma but does not effect pRb protein expression. It is probable that $\mathrm{pRb}$ is inactivated by other mechanisms, namely phosphorylation, in myeloma. A high incidence of $13 \mathrm{q}$ deletions has been reported in patients with multiple myeloma who have a preceding history of MGUS, suggesting that it may be involved in the transformation of MGUS into myeloma. ${ }^{74}$ An association between $13 \mathrm{q}$ deletions and the $\mathrm{t}(4 ; 14)$ translocation has also been reported..$^{39}{ }^{63}$ There is a need for prospective studies of patients with MGUS and myeloma to confirm these findings. Clearly, there are a large number of unanswered questions relating to the identification of the relevant deleted gene(s) on 13q, the consequences of such deletions on myeloma cell biology, and the relevance and timing of these deletions in myeloma and MGUS.

\section{MOLECULAR ABNORMALITIES IN MULTIPLE MYELOMA INCREASE WITH DISEASE PROGRESSION Loss of function of the cyclin D kinase inhibitors}

The cyclin D kinase (CDK) inhibitors are important in the control of progression through the cell cycle. The $\mathrm{pl} 6^{\mathrm{INK} 4 \mathrm{~A}}(\mathrm{pl6})$ protein is an inhibitor of CDK4 and CDK6. Hypermethylation leading to deactivation of the pl6 gene is frequently seen in myeloma, ${ }^{78}$ more frequently in advanced disease and in myeloma cell lines. ${ }^{79}$ Treatment with the demethylating agent 5-deoxyazacytidine restores pl6 protein expression and induces Gl growth arrest in patient plasma cell leukaemia cells and in myeloma cell lines. ${ }^{79}$ This evidence suggests that inactivation of the pl6 gene by hypermethylation may be associated with decreased growth control and with progression of myeloma. Homozygous deletions of genes encoding the CDK inhibitors $\mathrm{pl} 5^{\text {INK4A }}, \mathrm{pl}^{\text {INK4A }}$, and $\mathrm{pl} 8^{\text {INK4A }}$ may also occur in some patients with multiple myeloma. ${ }^{80}$ There are two recent studies looking at inactivation of $\mathrm{pl}^{{ }^{\mathrm{INK} 4 \mathrm{~A}}}$ and pl5 ${ }^{\text {INK4A }}$ by hypermethylation of the gene promoters. One study suggested that methylation was an early immortalising event in MGUS but was not associated with transformation into myeloma.$^{81}$ In contrast, the other study suggested that hypermethylation of pl6 ${ }^{\text {INK4A }}$ appears during the progression of myeloma. ${ }^{82}$ Therefore, the inactivation of pl6 by promoter methylation may occur both early in the disease and as a late event.

\section{"P21 appears to be expressed constitutively in most} plasma cells in myeloma"

P2 $1^{\text {WAF1 }}$ (p21) inhibits cell proliferation by both p53 dependent and independent mechanisms and probably protects the cell from apoptosis by the induction of cell cycle arrest and subsequent DNA repair. In contrast to normal B cells, in which it is not detected, it appears to be expressed constitutively in most plasma cells in myeloma. ${ }^{82}$ IL-6 downregulates its expression and interferon $\gamma$ upregulates its expression, and this effect correlates with the Gl to S transition induced by IL-6 in myeloma cells. ${ }^{83}$ P2 1 expression may induce resistance to apoptosis by chemotherapy/radiotherapy in myeloma plasma cells.

\section{The ras oncogenes in multiple myeloma}

The human ras genes ( $\mathrm{H}$-ras, $\mathrm{K}$-ras, $\mathrm{N}$-ras) encode three proteins, which are membrane associated guanosine triphosphatases (GTPases), and which function as crucial signalling intermediates involved in the responses to multiple growth factors. N-ras and K-ras are mutated in many cancers. The frequency of ras mutations is about $39 \%$ in newly diagnosed patients with multiple myeloma, but this increases significantly with the duration of the disease. Mutations of N-ras and K-ras are rarely detected in solitary plasmacytomas and MGUS, but are seen more frequently in myeloma (in $9-30 \%$ of patients) and in most patients with terminal disease or plasma cell leukaemia $(63.6-70 \%){ }^{84}{ }^{85}$ Mutations of ras are associated with more aggressive disease and a poor clinical outcome. ${ }^{86} \mathrm{~N}$-ras codon 61 mutations seem more frequent than those involving codons 12 and 13, or K-ras mutations. ${ }^{85}$ Activating mutations of $\mathrm{N}$-ras or K-ras in myeloma may result in independence from IL-6 and the suppression of apoptosis. ${ }^{85}{ }^{87}$ Therefore, an attractive hypothesis is that in early disease, where myeloma cell growth seems strictly dependent on the presence of IL-6, the paracrine secretion of IL- 6 in the bone marrow microenvironment activates ras pathways. With disease progression, activating mutations of N-ras or K-ras occur, leading to activation of this pathway independently of IL-6, thus allowing an IL-6 independent tumour expansion and dissemination outside the bone marrow. Recently, Kalakonda et al detected subsets of N-ras codon 61 mutated plasma cells in all 34 patients with myeloma examined, suggesting that this is a mandatory event in the pathogenesis 
of multiple myeloma. ${ }^{88}$ These hypotheses require verification by examining ras functions and pathways at different stages of myeloma.

\section{p53 mutations in multiple myeloma}

The tumour suppressor gene p53 is probably the most frequently mutated gene in human cancer, mutations being found in a wide range of solid tumours and haemopoietic malignancies. Wild-type p53 is a sequence specific DNA binding protein that acts to induce gene expression and overall is associated with the suppression of growth through $\mathrm{p} 2 \mathrm{l} /$ wafl as a response to DNA damage. It is part of the complex pathways ensuring the maintenance of the genome, allowing either DNA repair or alternatively activating cellular apoptosis. It is postulated to favour apoptosis by inducing the synthesis of bax and reducing the synthesis of bcl-2, thereby affecting the balance between cell growth and death. Overexpression of wild-type $\mathrm{p} 53$ can suppress autocrine IL- 6 production and the proliferation of U266 cells. ${ }^{89}$ It is frequently mutated in myeloma cell lines but without apparent correlation with autonomous, IL-6 independent cell growth. ${ }^{90}$ However, p53 mutations are infrequent in multiple myeloma and appear to be a late event in the disease. They occur in only $5 \%$ of inactive myelomas and in $20-40 \%$ of acute plasma cell leukaemias. ${ }^{84} 91$ Monoallelic deletions appear to be more common using FISH and appear to be associated with a worse survival. ${ }^{92}$ Monoallelic deletions alone would not be expected to impair p53 function and the mechanisms of impaired p 53 function in myeloma need further study.

\section{The retinoblastoma locus in multiple myeloma}

The $\mathrm{Rb}$ tumour suppressor gene is located on chromosome $13 \mathrm{q}$ and codes for a nuclear phosphoprotein $(\mathrm{pRb})$ that suppresses the Gl to S transition in the cell cycle by inhibiting E2F mediated transactivation of a variety of genes involved in initiating DNA synthesis, such as c-myc, b-myb, cdc2, dihydrofolate reductase, and thymidine kinase. Hypophosphorylated or dephosphorylated pRb is activated and binds E2F, thereby inducing cell cycle arrest; in contrast, phosphorylated pRb is inactivated and cannot bind E2F, thereby promoting the entry of cells into S phase. Mutations of the Rb gene or protein contribute to cellular transformation in many types of malignancies. Elimination or inactivation of both $\mathrm{Rb}$ copies is required for the manifestation of the tumorigenic phenotype. Myeloma cells may show a very strong expression of $\mathrm{pRb}$, mostly in its phosphorylated form. ${ }^{93}$

Despite monoallelic deletion of $\mathrm{Rb}$ in over half of myeloma samples (see above on $13 \mathrm{q}$ deletions), biallelic loss of the $\mathrm{Rb}$ gene is infrequent. ${ }^{94}{ }^{95}$ In addition, monoallelic lesions do not have an effect on the expression of $\mathrm{pRb}$, and no mutations or rearrangements of $\mathrm{Rb}$ have been described.

\section{"The role (if any) that the loss of pRb plays in myeloma transformation remains unclear"}

There is evidence that $\mathrm{pRb}$ may contribute to cell growth in multiple myeloma probably by inactivation via excessive phosphorylation. The incubation of myeloma cells with $\mathrm{Rb}$ antisense oligonucleotides triggers IL-6 secretion and cell proliferation. ${ }^{93}$ The overexpression of wild-type $\mathrm{pRb}$ suppresses the autocrine IL- 6 production and proliferation of U266 cells. ${ }^{89}$ In IL-6 responsive myeloma cells, stimulation via IL-6 pathways further shifts $\mathrm{pRb}$ from its dephosphorylated to its phosphorylated form, thereby promoting myeloma cell growth. ${ }^{93}$ Hyaluronic acid in the bone marrow microenvironment can stimulate this pathway through unknown mechanisms, presumably involving by potentiating the binding of IL-6 to its receptor. ${ }^{96}$ Despite this evidence, the role (if any) that the loss of $\mathrm{pRb}$ plays in myeloma transformation remains unclear.
Abnormalities of the fas gene in multiple myeloma

The Fas antigen, CD95, is a $45 \mathrm{kDa}$ transmembrane protein that can induce apoptosis when bound to the Fas ligand (FasL). Point mutations of the fas gene have been described in patients with congenital autoimmune disease. Recently, similar mutations have been described in patients with myeloma, and are associated with either lack of expression or decoy receptors, which by virtue of alterations in the cytoplasmic signalling domain prevent Fas-L induced apoptosis. ${ }^{97}$ In addition, the Fas-L expressed on myeloma cells has been shown to induce apoptosis in erythroid progenitors, contributing to the anaemia seen in this disease. ${ }^{98}$ However, the role of these mutations and Fas antigenic expression in the development or maintenance of myeloma remains unclear.

\section{C-myc in multiple myeloma}

C-myc, the cellular homologue of the transforming gene $\mathrm{v}$-myc from the oncogenic avian retrovirus, appears to play a central role in controlling proliferation, differentiation, and apoptosis. The classic $\mathrm{t}(8 ; 14), \mathrm{t}(2 ; 8)$, or $\mathrm{t}(8 ; 22)$ translocations that juxtapose a c-myc locus with an Ig loci are the hallmark of Burkitt's lymphoma and murine plasmacytomas. In contrast, in human myeloma the classic $\mathrm{t}(8 ; 14)$ occurs in less than $5 \%$ of cases.

There are two recent studies using FISH to analyse c-myc rearrangements. Shou et al identified c-myc rearrangements in 19 of 20 cell lines and in seven of 14 primary myeloma tumours. ${ }^{71}$ In contrast Avet-Loiseau and colleagues ${ }^{72}$ identified c-myc arrangements in a much lower number of patients with myeloma (15\%) and cell lines (55\%), and showed a correlation with high $\beta 2$ microglobulin values. Both sets of authors showed that these translocations are often complex, often not reciprocal, and frequently do not involve the $\mathrm{IgH}$ locus or involve breakpoints in the IgH region that are not usually associated with class switch recombination. Both identified a wide variation in the proportion of plasma cells with the rearrangement, suggesting that c-myc rearrangements are a late event in myeloma. However, Avet-Loiseau and colleagues ${ }^{72}$ showed a similar incidence in patients at relapse compared with those newly diagnosed ( $16 \% v 10 \%)$. The mechanism of these events and relevance to myeloma progression are not clear.

\section{$\mathrm{Bcl}-2$ in multiple myeloma}

The membrane protein Bcl-2 is a highly conserved, ubiquitous membrane protein associated with the outer membranes of mitochondria, nuclei, and the endoplasmic reticulum with a regulatory role in apoptosis. Bcl-2 forms inactivating or activating heterodimers with other proteins encoded by the genes of the bcl-2 superfamily (Bax, Bcl- $\mathrm{X}_{\mathrm{S}^{\prime}}$ Bak, Bad, Bcl- $\mathrm{X}_{\mathrm{L}^{\prime}}$ Mcl-1, NR-13, Al, Bcl-W) and blocks apoptosis. The classic Bcl-2 translocation, $\mathrm{t}(14 ; 18)$, seen in follicular lymphoma is rare in myeloma. Despite this, overexpression of $\mathrm{Bcl}-2$ is seen in most patients with multiple myeloma and in myeloma cell lines. ${ }^{99}{ }^{100}$ High concentrations of Bcl-2 protein probably mediate the resistance of multiple myeloma cells to apoptosis induced by dexamethasone, IL-6 deprivation, staurosporine, or other drugs. ${ }^{101}{ }^{102}$ However, it is unclear whether expression differs from that seen in non-malignant plasma cells and whether it correlates with clinical outcome. ${ }^{100}$ Recently, using immunofluorescence and immunoenzymatic methods, Miguel-Garcia et al showed an increase in both the number of bcl-2 positive plasma cells and the intensity of expression of bcl-2 as the disease progressed, and also a significant difference between malignant gammopathies and reactive plasmacytosis. ${ }^{103}$

\section{PTEN in multiple myeloma}

PTEN is a phosphatase that negatively controls the antiapoptotic action of akt phosphorylation. Loss of PTEN expression has been detected in many solid tumours and more 
recently in myeloma cell lines, suggesting that it may play a role in the pathogenesis of myeloma. ${ }^{104}$

\section{GENE ARRAY ANALYSIS IN MULTIPLE MYELOMA}

Gene expression analysis is a relatively new technique that can look at the expression patterns of thousands of genes pertinent to various biological functions. The largest study to date in multiple myeloma is that of Zhan et al, ${ }^{105}$ which identified four distinct subgroups of myeloma on the basis of their expression pattern. Group MMI was similar to normal plasma cells and MGUS, whereas group MM4 was similar to cell lines. Genes involved in DNA metabolism and cell cycle control were overexpressed in MM4 compared with MMl. One hundred and twenty new candidate disease genes were identified that discriminate normal and malignant plasma cells. Many of these genes are involved in adhesion, apoptosis, cell cycle, drug resistance, growth arrest, oncogenesis, signalling, and transcription.

\section{CYTOKINES AND BONE MARROW MICROENVIRONMENT}

The interaction of myeloma cells with stromal cells via adhesion molecules and both the paracrine and autocrine production of cytokines are crucial in the pathogenesis of myeloma and its associated bone disease. IL-6 is clearly the most important cytokine in myeloma biology and is predominantly produced in a paracrine fashion. ${ }^{106}$ Normally, IL-6 causes B cell differentiation, but in myeloma it causes proliferation and inhibits apoptosis. ${ }^{106}$ The IL-6 receptor consists of two subunits, IL-6R $\alpha$ and a transmembrane signal transducer, gp130, shared by other cytokines. The effects of these cytokines that share the gpl30 subunit (namely, IL-11, ciliary neurotrophic factor, oncostatin $\mathrm{M}$, leukaemia inhibitory factor, and cardiotrophin 1) in myeloma is not clear. ${ }^{5}$ Both subunits of the receptor can exist in a soluble form; the soluble IL-R $\alpha$ subunit has a similar affinity for IL-6, and has the ability to mediate signalling via bound gpl30 and have an agonist effect. In contrast, soluble gp130 at high concentrations may competitively inhibit the growth promoting effects of IL-6-IL-6R complexes. The downstream effects of the binding of IL-6 to the IL-6R result in tyrosine phosphorylation and homodimerisation of gpl30, with activation of the Janus kinase family of tyrosine kinases. Three downstream pathways are activated, the STAT3-STAT3 pathway, STATI-STAT3 pathway, and finally the Ras-MAPK pathway. ${ }^{105}$ The signalling cascades that mediate the anti-apoptotic effects of IL-6 are different from those that mediate growth. ${ }^{107}$ In myeloma, there is a failure of downregulation of IL-6R $\alpha$ compared with normal plasma cells. ${ }^{108}$ Both STAT3 and STAT1 appear to be constitutively active in IL-6 responsive and non-responsive myeloma cells and their role in myeloma is not clear. ${ }^{5}$ The activation of the Ras-MAPK pathway correlates with the proliferative response of myeloma cells to IL-6, and Ras mutations appear to result in activation of this pathway in the absence of IL- $6 .{ }^{5}$ The adhesion of myeloma cells within the bone marrow microenvironment results in the increased expression of IL-6 by stromal cells and the increased production of several important cytokines. These include vascular endothelial growth factor (VEGF), IL-1 $\beta$, IL-10, tumour necrosis factor $\alpha$ (TNF- $\alpha$ ), parathyroid hormone related protein, transforming growth factor $\beta$ (TGF- $\beta$ ), matrix metalloproteinase 1 , osteoprotegerin $(\mathrm{OPG}) /$ receptor activator of nuclear factor $\kappa \mathrm{B}$ (RANKL), macrophage inflammatory protein $l \alpha$, FGFs, insulin growth factors (IGFs), and hepatocyte growth factors (HGFs). ${ }^{5109-112}$ The role of these cytokines in the pathogenesis of myeloma is less well understood than that of IL-6. They clearly play a role in angiogenesis (VEGF, FGFs, HGFs), osteoclast activation (IL-1 $\beta$, RANKL, HGFs), and immunodeficiencies (TGF- $\beta$, VEGF), and have direct effects on myeloma cells
(TNF- $\alpha$, IGFs, IL-1 $\beta$, VEGF, possibly others). Osteoclast differentiation and activity is promoted by the binding of the osteoblastic RANKL ligand to its receptor RANKL and this interaction is inhibited by a decoy receptor, OPG. In myeloma, there is an imbalance in RANKL and OPG expression that leads to bone destruction. ${ }^{109} 113114$ This imbalance probably results from alterations in stromal cell expression of RANKL and OPG following cell to cell contact with myeloma cells. ${ }^{113}$ There are a large number of adhesion molecules that are important in myeloma-stromal cell interactions, which lead to both cytokine induction and direct effects on myeloma cell growth. ${ }^{107}$ Myeloma cell interaction with the extracellular matrix is also important. Recently, direct binding of myeloma cells to fibronectin has been shown to increase drug resistance by upregulating $\mathrm{p} 27,{ }^{115}$ and the binding of myeloma cells to hyaluronic acid synergises IL-6 signalling. ${ }^{96}$

"Normally, IL-6 causes B cell differentiation, but in myeloma it causes proliferation and inhibits apoptosis"

Human herpesvirus 8 has been reported to infect the dendritic cells of patients with myeloma and to produce a viral analogue of IL-6. ${ }^{116}$ However, several groups have failed to confirm this, ${ }^{117}$ and the role of human herpesvirus 8 in the pathogenesis of human myeloma has remained controversial. Myeloma can enter an extramedullary phase, with alterations in the adhesion molecule profile (a reduction in CD56 and very late antigen 4) and growth factor independence. Eventually, patients become resistant to chemotherapy with expression of a multidrug resistance phenotype.

\section{PROGNOSTIC VALUE OF CHROMOSOMAL AND GENETIC ABNORMALITIES IN MULTIPLE MYELOMA}

There are currently only limited data relating to the prognostic value of these karyotypic and molecular abnormalities, and many have combined the results of treated and untreated patients into one category. The vast majority of the data relate to conventional cytogenetics, which therefore immediately excludes most patients without detectable karyotypic abnormalities. Further studies are necessary to define the prognostic value of the more recently described molecular abnormalities. The presence of an abnormal karyotype does not necessarily imply a poor prognosis because both conventional cytogenetics and flow cytometry have shown hyperdiploidy to be associated with a relatively good prognosis. ${ }^{1622118}$ Monosomy 13 has been identified as the most important adverse molecular marker to date. ${ }^{75} 77118$ However, as stated above the study of Shaugnessy et al, ${ }^{76}$ which found that $86 \%$ of patients had a 13q deletion, highlights the need to identify the crucial deleted region on 13q. Hypodiploidy is also an adverse prognostic factor. ${ }^{118}$ The $\mathrm{t}(11 ; 14)$ translocation or involvement of $1 \mathrm{lql} 3$ is not now thought to be associated with a worse prognosis, ${ }^{3963}$ as had previously been thought. ${ }^{104151}$ Ho and colleagues found that 12 of 21 patients had an IgH translocation, but failed to show a significant difference between patients with $\mathrm{IgH}$ rearrangements and those without in terms of survival, $\beta 2$ microglobulin value, or serum thymidine kinase. Avet-Loiseau and colleagues ${ }^{39}$ clearly showed that $\mathrm{t}(4 ; 14)$ was associated with a worse prognosis, but there were no prognostic differences between patients with or without other IgH rearrangements.

\section{DISCUSSION}

The search for a primary cytogenetic event in multiple myeloma has proved difficult because, by the very nature of the disease process, most karyotypes have already evolved by the time of diagnosis. The transformation of MGUS to myeloma and the disease progression in myeloma are associated with increasing chromosomal instability, enabling the 


\section{Take home messages}

- Multiple myeloma is a malignant tumour of plasma cells which usually progresses through a stepwise process and has a median survival of two to three years

- Multiple myeloma may or may not originate from a common benign plasma cell tumour called monoclonal gammopathy of uncertain significance (MGUS)

- Karyotypic instability is seen at the earliest stage of the disease and increases with disease progression, leading to extreme genetic abnormalities similar to solid tumours

- It is only with the advent of fluorescence in situ hybridisation that the extent of karyotypic abnormalities has become recognised

- Translocations involving the immunoglobulin heavy chain region $(\lg \mathrm{H})$ on chromosome $14 \mathrm{q} 32$ have been identified in $50 \%$ of patients with MGUS, $65 \%$ of myelomas, and $>90 \%$ of myeloma cell lines, and are clearly important in the pathogenesis of most myelomas

- These translocations are an early event, which occurs during class switch recombination and leads to dysregulation of translocated genes under the influence of the $\mathrm{lgH}$ enhancers on $14 q 32$

- These translocations involve several partner chromosomes, with four recurrent partner chromosomes accounting for about $50 \%$ of translocations

- Chromosome 13q deletions have been recognised as an important adverse prognostic factor in myeloma and there is currently a search for the commonly deleted gene(s)

- Most genetic abnormalities found in myeloma relate to relapsed, progressive disease and little is known about the initial immortalising and transforming events

- Karyotypic instability is an early feature of this disease and understanding abnormalities in DNA metabolism and repair is clearly crucial in this disease

- Biologically based treatments are currently under evaluation and hopefully will eventually lead to an improved outcome for these patients

malignant cell clone to survive and proliferate independently of the bone marrow microenvironment. Karyotypic instability is clearly present at the earliest stages of the disease. These abnormalities reflect structural or regulatory abnormalities of DNA metabolism, which are not currently well understood, but are similar to abnormalities seen in solid tumours and in non-homologous end joining/p53 double knockout mice. ${ }^{27} \mathrm{~A}$ chromosome translocation into the heavy chain switch region appears to be a common, early event in multiple myeloma occurring during class switch recombination. However, these translocations do not appear to occur in at least 30-50\% of patients at presentation. In addition, despite some recurrent partner chromosomes there are promiscuous numbers of new partner chromosomes involved, some recurrently, and the biological consequences of such translocations are poorly understood. Despite a convincing role for these translocations in the pathogenesis of some myelomas, their exact role in the development of myeloma is unclear. The true oncogenic potential of an oncogene translocated to $14 \mathrm{q} 32$ may only arise after further mutation, either within the oncogene itself (for example, FGFR3 and $t(4 ; 14)(\mathrm{pl} 6 ; \mathrm{q} 32))$ or by mutation in the control regions, although this has only been identified in a small number of cases.

"A chromosome translocation into the heavy chain switch region appears to be a common, early event in multiple myeloma occurring during class switch recombination"

It is also clear that the deletion of $13 \mathrm{q}$ adversely affects prognosis, but the crucial gene(s) are yet to be identified, and the relevance of $13 \mathrm{q}$ to myeloma and MGUS development, transformation, and progression has yet to be determined.

Despite the large number of potentially transforming events described in this disease the similar phenotype seen in patients with myeloma-an accumulation of malignant plasma cells-suggests that the fate of the transformed B cell is limited whatever the transforming event. ${ }^{27}$

Despite a wealth of data, we clearly have a limited insight into the pathogenesis of this disease. Understanding DNA metabolism and damage response pathways is clearly important.

Despite chemotherapy, this disease has a universally poor outcome. However, more biologically based treatments, which target the mechanisms whereby myeloma cells grow and proliferate in the bone marrow environment, are currently being investigated. Thalidomide and its derivatives have several mechanisms of action including direct effects on myeloma cells, immunomodulatory effects, cytokine modulation, and anti-angiogenic action. Other biologically based treatments being investigated include recombinant osteoprotegerin, ${ }^{114}$ FGFR inhibitors for patients with the $t(4 ; 14)$ translocation, ${ }^{119}$ ras pathway inhibitors, and inhibitors of the transcription factor NF- $\mathrm{kB}$, including proteosome inhibitors. ${ }^{120}{ }^{121}$ Hopefully, biologically based treatments will eventually lead to a better outcome for patients with myeloma compared with conventional based chemotherapy.

\section{REFERENCES}

1 Zandecki M, Lai JL, Facon T. Multiple myeloma: almost all patients are cytogenetically abnormal. Br J Haematol 1996;94:217-27.

2 Drach J, Angerler J, Schuster J, et al. Interphase fluorescence in situ hybridisation identifies chromosomal abnormalities in plasma cells from patients with monoclonal gammopathy of undetermined significance. Blood 1995;86:3915-21.

3 Zandecki M, Obein V, Bernardi F, et al. Monoclonal gammopathy of undetermined significance: chromosome changes are a common finding within plasma cells. BrJ Haematol 1995:90:693-6.

4 Fonseca R, Aguayo P, Ahmann GJ, et al. Translocations at $14 q 32$ are common in patients with the monoclonal gammopathy of undetermined significance (MGUS) and involve serial partner chromosomes [abstract]. Blood 1999;10(suppl 1):2943.

5 Hallek M, Bersagel PL, Anderson K. Multiple myeloma: increasing evidence for a multistep transformation process. Blood 1998;91:3-21.

6 DeWald G, Kyle R, Hicks G, et al. The clinical significance of cytogenetic studies in 100 patients with multiple myeloma, plasma cell leukaemia or amyloidosis. Blood 1985;66:380-90.

7 Gould J, Alexanian R, Goodacre A, et al. Plasma cell karyotype in multiple myeloma. Blood 1988;7:453-6.

8 Weh H, Gutensohn K, Selbach J, et al. Karyotype in multiple myeloma and plasma cell leukaemia. Eur J Cancer 1993;29:1269-73.

9 Sawyer JR, Waldron JA, Jagannath S, et al. Cytogenetic findings in 200 patients with multiple myeloma. Cancer Genet Cytogenet 1995;82:41-9.

10 Tricot G, Barlogie B, Jagannath S, et al. Poor prognosis in multiple myeloma is associated only with partial or complete deletions of chromosome 13 or abnormalities involving $11 \mathrm{q}$ and not with other karyotype abnormalities. Blood 1995:86:4250-6.

11 Lai JL, Zandecki M, Mary JY, et al. Improved cytogenetics in multiple myeloma: a study of 151 patients including 117 patients at diagnosis. Blood 1995;85:2490-7

12 Calasanz MJ, Cigudosa JC, Odero MD, et al. Cytogenetic analysis of 280 patients with multiple myeloma and related disorders: primary breakpoints and clinical correlations. Genes Chromosomes Cancer 1997; 18:84-93.

13 Seong C, Delasalle K, Hayes K, et al. Prognostic value of cytogenetics in multiple myeloma. Br J Haematol 1998;101:189-94.

14 Facon T, Lai JL, Preudhomme C, et al. Improved cytogenetic analysis of bone marrow plasma cells after cytokine stimulation in multiple myeloma: a report on 46 patients. Br J Haematol 1993;84:743-5.

15 Smadja NV, Louvet C, Isnard F, et al. Cytogenetic study in multiple myeloma at diagnosis: comparison of two techniques. Br J Haematol 1995:90:619-24

16 Smadja NV, Fruchart C, Isnard F, et al. Chromosomal analysis in multiple myeloma: cytogenetic evidence of two different diseases. Leukemia 1998;12:960-9.

17 Latreille J, Barlogie B, Gohde W, et al. Cellular DNA content as a marker of human multiple myeloma. Blood 1980;55:403-8.

18 Barlogie B, Alexanian R, Dixon D, et al. Prognostic implications of tumor cell DNA and RNA content in multiple myeloma. Blood 1985;66:338-41

19 Lee W, Han K, Drut RM, et al. Use of fluorescence in situ hybridisation for retrospective detection of aneuploidy in multiple myeloma. Genes Chromosomes Cancer 1993;7:137-43. 
20 Drach J, Schuster J, Nowotny H, et al. Multiple myeloma: high incidence of chromosomal aneuploidy as detected by interphase fluorescence in situ hybridisation. Cancer Res 1995;55:3854-9.

21 Flactif $M$, Zandecki M, Lai JL, et al. Interphase fluorescence in situ hybridisation as a powerful tool for the detection of aneuploidy in multiple myeloma. Leukemia 1995;9:2109-14.

22 Tricot G, Sawyer JR, Jagannath S, et al. Unique role of cytogenetics in the prognosis of patients with myeloma receiving high-dose therapy and autotransplants. J Clin Oncol 1997;15:2659-66.

23 Avet-Loiseau H, Andree-Ashley LE, Moore D, et al. Molecular cytogenetic abnormalities in multiple myeloma and plasma cell leukaemia measured using comparative genomic hybridisation. Genes Chromosomes Cancer 1997; 19:124-33.

24 Cigudosa JC, Rao PH, Calasanz M, et al. Characterization of nonrandom chromosomal gains and losses in multiple myeloma by comparative genomic hybridisation. Blood 1998;91:3007-10.

25 Rao PH, Cigudosa JC, Ning Y, et al. Multicolor spectral karyotyping identifies new recurring breakpoints and translocations in multiple myeloma. Blood 1998;92:1743-8.

26 Sawyer JR, Lukacs JL, Munshi N, et al. Identification of new nonrandom translocations in multiple myeloma with multicolor spectral karyotyping. Blood 1998;92:4269-78.

27 Bergsagel PL, Kuehl WM. Chromosome translocations in multiple myeloma. Oncogene 2001;20:5611-22.

28 Korsmeyer SJ. Chromosomal translocations in lymphoid malignancies reveal novel protooncogenes. Annu Rev Immunol 1992;10:785-807.

29 Kuppers R, Dalla-Favera R. Mechanisms of chromosomal translocations in B cell lymphomas. Oncogene 2001;20:5580-94.

30 Bersagel PL, Chesi $M$, Nardini E, et al. Promiscuous translocations into immunoglobulin heavy chain switch regions in multiple myeloma. Proc Natl Acad Sci U S A 1996;93:13931-6.

31 Nishida K, Tamura A, Nakazawa N, et al. The lgG heavy chain gene is frequently involved in chromosomal translocations in multiple myeloma and plasma cell leukaemia as detected by in situ hybridisation. Blood 1997;90:526-34.

32 Avet-Loiseau H, Li JY, Facon T, et al. High incidence of translocations $t(11 ; 14)(q 13 ; q 32)$ and $t(4 ; 14)(p 16 ; q 32)$ in patients with plasma cell malignancies. Cancer Res 1998;58:5640-5.

33 Avet-Loiseau H, Brigaudeau C, Morineau N, et al. High incidence of cryptic translocations involving the lg heavy chain gene in multiple myeloma, as shown by fluorescence in situ hybridisation. Genes Chromosomes Cancer 1999;24:9-15.

34 Martelli ML, Gabrea A, Qi Y, et al. Immunoglobulin translocations in multiple myeloma: present in all cell lines but not all primary tumours. Blood 1999;10(suppl 1):2431.

35 Ho PJ, Brown RD, Pelka GJ, et al. Illegitimate switch recombinations are present in approximately half of primary myeloma tumors, but do not relate to known prognostic indicators or survival. Blood 2001;97:490-5.

36 Withdrawn.

37 Gabrea A, Bergsagel PL, Chesi M, et al. Insertion of excised lgH switch sequences causes overexpression of cyclin DI in a myeloma tumour cell. Molecular Cell 1999;3:119-23.

38 Pratt G, Fenton JAL, Davies FE, et al. Insertional events as well as translocations may arise during aberrant immunoglobulin switch recombination in a patient with multiple myeloma. Br J Haematol $2001 ; 112: 388-91$

39 Avet-Loiseau H, Facon T, Grosbois B, et al. Oncogenesis of multiple myeloma: $14 q 32$ and $13 q$ chromosomal abnormalities are not randomly distributed but correlate with natural history, immunological features and clinical presentation. Blood 2002;99:2185-91

40 Fonseca R, Blood EA, Oken MM, et al. Myeloma and the $t(11 ; 14)(q 13 ; q 32)$; evidence for a biologically defined unique subset of patients. Blood 2002;99:3735-41

41 Hayman SR, Bailey R, Jalal SM, et al. Translocations involving the immunoglobulin heavy-chain locus are possibly early events in patients with primary systemic amyloidosis. Blood 2001;98:2266-8.

42 Fonseca R, Witzig TE, Gertz MA, et al. Multiple myeloma and the translocation $+(11 ; 14)(q 13 ; q 32)$ : a report on 13 cases. Br J Haematol 1998;101:296-301.

43 Williams ME, Swerdlow SH, Rosenberg CL, et al. Chromosome 11 translocation breakpoints at the PRAD1/cyclin D1 gene locus in centrocytic lymphoma. Leukemia 1993;7:241-5

44 Janssen JWG, Vaandrager JW, Heuser T, et al. Concurrent activation of a novel putative transforming gene, myeov, and cyclin DI in a subset of multiple myeloma cell lines with a $t(11 ; 14)(q 13 ; q 32)$. Blood 2000;95:2691-8.

45 Ronchetti D, Finelli P, Richelda R, et al. Molecular analysis of $11 \mathrm{q} 13$ breakpoints in multiple myeloma. Blood 1999;93:1330-7

46 Seto M, Yamamoto K, lida S, et al. Gene rearrangement and overexpression of PRAD1 in lymphoid malignancy with t(11;14)(q13;q32) translocation. Oncogene 1992;7:1401-6.

47 Raynaud SD, Bekri S, Leroux D, et al. Expanded range of $11 \mathrm{q} 13$ breakpoints with differing patterns of cyclin DI expression in B-cell malignancies. Genes Chromosomes Cancer 1993;8:80-7.

48 Meeus P, Stul MS, Mecucci C, et al. Molecular breakpoints of t(1 1;14)(q13;q32) in multiple myeloma. Cancer Genet Cytogenet 1995;83:25-7.

49 Chesi M, Bergsagel PL, Brents LA, et al. Dysregulation of cyclin DI by translocation into an lgH gamma switch region in two multiple myeloma cell lines. Blood 1996;88:674-81.

50 Komatsu H, lida S, Yamamoto K, et al. A variant chromosome translocation at 11 q 13 identifying PRAD1/cyclin D1 as the BCL-1 gene. Blood 1994;84:1226-31.
51 Lai JL, Michaux L, Dastugue N, et al. Cytogenetics in multiple myeloma: a multicenter study of 24 patients with $+(11 ; 14)(q 13 ; q 32)$ or its variant. Cancer Genet Cytogenet 1998;104:133-8.

52 Finelli $\mathbf{P}$, Fabris $S$, Zagano $S$, et al. Detection of $t(4 ; 14)(p 16.3 ; q 32)$ chromosomal translocation in multiple myeloma by double-color fluorescent in-situ hybridisation. Blood 1999;94:724-32.

53 Malgeri U, Baldini L, Perfetti V, et al. Detection of $t(4 ; 14)(p 16.3 ; q 32)$ chromosomal translocation in multiple myeloma by reverse transcription-polymerase chain reaction analysis of IGH-MMSET fusion transcripts. Cancer Res 2000;60:4058-61.

54 Chesi M, Nardini E, Lim RSC, et al. The $t(4 ; 14)$ translocation in myeloma dysregulates both FGFR3 and a novel gene, MMSET, resulting in lgH/MMSET hybrid transcripts. Blood 1998;92:3025-34.

55 Chesi M, Nardini E, Brents LA, et al. Frequent translocation $\dagger(4 ; 14)(p 16.3 ; q 32.3)$ in multiple myeloma is associated with increased expression and activating mutations of fibroblast growth factor receptor 3. Nat Genet 1997; 16:260-4

56 Stec I, Wright TJ, van Ommen GJB, et al. WHSC-1, a 90 kb SET domain-containing gene, expressed in early development and homologous to a drosophila dysmorphy gene maps in the Wolf-Hirschhorn syndrome critical region and is fused to $\lg \mathrm{H}$ in $\mathrm{t}(4 ; 14)$ multiple myeloma. Hum Mol Genet 1998;7:1071-82.

57 Plowright EE, Li Z, Bergsagel PL, et al. Ectopic expression of fibroblast growth factor receptor 3 promotes myeloma cell proliferation and prevents apoptosis. Blood 2000;95:992-8.

58 Chesi $M$, Brents LA, Ely SA, et al. Activated fibroblast growth factor receptor 3 is an oncogene that contributes to tumor progression in multiple myeloma. Blood 2001;97:729-36.

59 Li Z, Zhu YX, Plowright EE, et al. The myeloma associated oncogene fibroblast growth factor receptor 3 is transforming in hematopoietic cells. Blood 2001;97:2413-19.

60 Intini D, Baldini L, Fabris S, et al. Analysis of FGFR3 gene mutations in multiple myeloma patients with $+(4 ; 14)$. Br J Haematol 2001;114:362-4.

61 Ronchetti D, Greco A, Compasso S, et al. Deregulated FGFR3 mutants in multiple myeloma cell lines with $+(4 ; 14)$ : comparative analysis of Y373C, K650E and the novel G384D mutations. Oncogene 2001;20:3553-62.

62 Still IH, Vince $P$, Cowell JK. The third member of the transforming acidic coiled coil-containing gene family, TACC 3 , maps in 4 p 16, close to the translocation breakpoints in multiple myeloma, and is upregulated in various cancer cell lines. Genomics 1999;58:165-70.

63 Fonseca R, Oken MM, Greipp PR. The $t(4 ; 14)(p 16.3 ; q 32)$ is strongly associated with chromosome 13 abnormalities in both multiple myeloma and monoclonal gammopathy of uncertain significance. Blood 2001;98:1271-2

64 Nishizawa M, Kataoka K, Goto N, et al. V-maf, a viral oncogene that encodes a "leucine zipper" motif. Proc Natl Acad Sci U S A 1989:86:7711-15.

65 Kataoka K, Nishizawa M, Kawai S. Structure-function analysis of the maf oncogene product, a member of the b-Zip protein family. J Virol 1993;67:2133-41

66 Bednarek AK, Keck-Waggoner CL, Daniel RL, et al. WWOX, the FRA 16D gene, behaves as a suppressor of tumor growth. Cancer Res $2001 ; 61: 8068-73$

67 Shaughnessy J, Gabrea A, Ying Q, et al. Cyclin D3 at $6 p 21$ is dysregulated by recurrent chromosomal translocations to immunoglobulin loci in multiple myeloma. Blood 2001;98:217-23

68 lida S, Rao PH, Butler M, et al. Deregulation of MUM1/IRF4 by chromosomal translocation in multiple myeloma. Nat Genet 1997; 17:226-30.

69 Hatzivassiliou G, Miller I, Takizawa J, et al. IRTA1 and IRTA2, novel immunoglobulin superfamily receptors expressed in $B$ cells and involved in chromosome 1q21 abnormalities in B cell malignancy. Immunity 2001;14:277-89

70 Sawyer JR, Lukacs JL, Thomas EL, et al. Multicolor spectral karyotyping identifies new translocations and a recurring pathway for chromosome loss in multiple myeloma. Br J Haematol 2001;112:167-74.

71 Shou Y, Martelli ML, Gabrea A, et al. Diverse karyotypic abnormalities of the c-myc locus associated with c-myc dysregulation and tumor progression in multiple myeloma. Proc Natl Acad Sci U S A 2000;97:228-33

72 Avet-Loiseau H, Gerson F, Magrangeas F, et al. Rearrangements of the c-myc oncogene are present in $15 \%$ of primary human multiple tumors. Blood 2001;98:3082-6

73 lida S, Rao PH, Nallasivam P, et al. The $+(9 ; 14)(\mathrm{p} 13 ; q 32)$ chromosomal translocation associated with lymphoplasmacytoid lymphoma involves the PAX-5 gene. Blood 1996;88:4110-17.

74 Avet-Loiseau H, Li JY, Morineau N, et al. Monosomy 13 is associated with the transition of monoclonal gammopathy of undetermined significance to multiple myeloma. Blood 1999;94:2583-9.

75 Zojer N, Konigsberg R, Ackermann J, et al. In multiple myeloma, deletion of 13 q 14 remains an independent adverse prognostic parameter despite its frequent detection by interphase FISH. Blood 2000;95: 1925-30

76 Shaughnessy J, Tian E, Sawyer J, et al. High incidence of chromosome 13 deletion in multiple myeloma detected by multiprobe interphase FISH. Blood 2000;96:1505-11.

77 Facon T, Avet-Loiseau H, Guillerm G, et al. Chromosome 13 abnormalities identified by FISH analysis and serum beta2-microglobulin produce a powerful myeloma staging system for patients receiving high-dose therapy. Blood 2001;97:1566-71.

$78 \mathrm{Ng} \mathrm{MHL}$, Chung YF, Lo KW, et al. Frequent hypermethylation of pl6 and p15 genes in multiple myeloma. Blood 1997;87:2500-6. 
79 Urashima M, Teoh G, Ogata A, et al. Role of CDK4 and p 16INK4A in interleukin-6 mediated growth of multiple myeloma. Leukemia 1997; 11:1957-63

80 Tasaka T, Berenson J, Vescio R, et al. Analysis of the p1 $6^{\text {INK4A }}$, pl $5^{\text {INKAA }}$ and $18^{\text {INKAA }}$ genes in multiple myeloma. Br J Haematol 1997;96:98-102.

81 Guillerm G, Gyan E, Wolowiec D, et al. p16 $6^{\text {INK4A }}$ and p1 $5^{\text {INK4b }}$ gene methylations in plasma cells from monoclonal gammopathy of undetermined significance. Blood 2001;98:244-6.

82 Uchida T, Kinoshita T, Ohno T, et al. Hypermethylation of pl6INK4A gene promoter during the progression of plasma cell dyscrasia. Leukemia 2001;15:157-65.

83 Urashima M, Teoh G, Chauhan D, et al. Interleukin 6 overcomes P2 $1{ }^{\text {WAF1 }}$ upregulation and $G 1$ growth arrest induced by dexamethasone and interferon- $\gamma$ in multiple myeloma cells. Blood 1997:90:279-89.

84 Portier M, Moles JP, Mazars GR, et al. P53 and RAS gene mutations in multiple myeloma. Oncogene 1992;7:2539-43.

85 Corradini $\mathbf{P}$, Ladetto $M$, Voena $C$, et al. Mutational activation of $\mathrm{N}$ - and K-ras oncogenes in plasma cell dyscrasias. Blood 1993;81:2708-13.

86 Liu $\mathbf{P}$, Leong T, Quam L, et al. Activating mutations of $\mathrm{N}$ - and K-ras in multiple myeloma show different clinical associations: analysis of the eastern cooperative oncology group phase III trial. Blood 1996;88:2699-706.

87 Billadeau D, Jelinek DF, Shah N, et al. Introduction of an activated $\mathrm{N}$-ras oncogene alters the growth characteristics of the interleukin 6-dependent myeloma cell line ANBL6. Cancer Res 1995;55:3640-6.

88 Kalakonda N, Rothwell DG, Scarffe JH, et al. Detection of N-Ras codon 61 mutations in subpopulations of tumor cells in multiple myeloma at presentation. Blood 2001:98:1555-60.

89 Liu P, Rowley M, Van Ness B. Wildtype Rb and p53 can suppress autocrine IL-6 production and proliferation of U266 myeloma cells [abstract]. Blood 1996;88(suppl 1): 100a

90 Mazars GR, Portier M, Zhang XG, et al. Mutations of the p53 gene in human myeloma cell lines. Oncogene 1993:8:1107.

91 Neri A, Baldini L, Trecca D, et al. P53 gene mutations in multiple myeloma are associated with advanced forms of malignancy. Blood 1993;81:128-35.

92 Drach J, Ackermann J, Fritz E, et al. Presence of a p53 gene deletion in patients with multiple myeloma predicts for short survival after conventional dose chemotherapy. Blood 1998:92:802-7.

93 Urashima M, Ogata A, Chauhan D, et al. Interleukin-6 promotes multiple myeloma cell growth via phosphorylation of retinoblastoma protein. Blood 1996;88:2219-27.

94 Zandecki $\mathbf{M}$, Facon T, Preudhomme $C$, et al. The retinoblastoma gene (RB-1) status in multiple myeloma: a report on 35 cases. Leuk Lymphoma $1995 ; 18: 497$

95 Juge-Morineau N, Mellerin MP, et al. High incidence of deletions but infrequent inactivation of the retinoblastoma gene in human myeloma cells. Br J Haematol 1995;91:664-7.

96 Vincent T, Jourdan M, Sy MS, et al. Hyaluronic acid induces survival and proliferation of human myeloma cells through an interleukin-6 mediated pathway involving the phosphorylation of retinoblastoma protein. J Biol Chem 2001;276:14728-36.

97 Hahne M, Rimoldi D, Schroter $M$, et al. Melanoma cell expression of Fas (Apo-1/CD95) ligand: implications for tumor immune escape. Science 1996;274:1302

98 Silvestris $\mathbf{F}$, Tucci $M$, Cafforio $P$, et al. Fas-L upregulation by highly malignant myeloma plasma cells: role in the pathogenesis of anaemia and disease progression. Blood 2001;97:1155-64.

99 Pettersson $M$, Jernberg-Wiklund $H$, Larsson LG, et al. Expression of the bcl-2 gene in human multiple myeloma cell lines and normal plasma cells. Blood 1992;79:495-502
100 Ong F, Nieuwkoop JA, De Groot-Swings GMS, et al. Bcl-2 protein expression is not related to short survival in multiple myeloma. Leukemia 1995; 9: 1282-4

101 Schwarze MMK, Hawley RG. Prevention of myeloma cell apoptosis by ectopic bcl-2 expression or interleukin 6 mediated up regulation of bcl- $\mathrm{X}_{\mathrm{L}}$. Cancer Res 1995;55:2262-5.

102 Tian E, Gazitt Y. The role of p53, bcl-2 and bax network in dexamethasone induced apoptosis in multiple myeloma cell lines. Int J Oncol 1996;8:719-26.

103 Miguel-Garcia A, Orero T, Matutes E, et al. Bcl-2 expression in plasma cells from neoplastic gammopathies and reactive plasmacytosis: a comparative study. Haematologica 1998;83:298-304.

104 Hyun T, Yam A, Pece S, et al. Loss of PTEN expression leading to high Akt activation in human multiple myelomas. Blood 2000;96:3560-8.

105 Zhan F, Hardin J, Kordsmeier B, et al. Global gene expression profiling of multiple myeloma, monoclonal gammopathy of undetermined significance and normal bone marrow plasma cells. Blood 2002;99:1745-57

106 Klein B, Zhang XG, Lu ZY, et al. Interleukin-6 in human multiple myeloma. Blood 1995;85:863-72.

107 Davies FE, Anderson KC. Novel therapeutic targets in multiple myeloma Eur J Haematol 2000;64:359-67.

108 Rawstron AC, Fenton JAL, Ashcroft J, et al. The IL-6 receptor alpha chain (CD126) is expressed by neoplastic but not normal plasma cells. Blood 2000;96:3880-6.

109 Tricot G. New insights into role of microenvironment in multiple myeloma. Lancet 2000;355:248-9.

110 Vacca A, Ribatti D, Presta $M$, et al. Bone marrow neovascularization, plasma cell angiogenic potential and matrix metalloproteinase-2 secretion parallel progression of multiple myeloma. Blood 1999;9:3064-73

111 Seidel C, Borset M, Hiertner O, et al. High levels of soluble syndecan-1 in myeloma derived bone marrow: modulation of hepatocyte growth factor activity. Blood 2000;96:3139-46.

112 Podar K, Yu-Tzu T, Davies FE, et al. Vascular endothelial growth factor triggers signaling cascades mediating multiple myeloma cell growth and migration. Blood 2001;98:428-35.

113 Giuliani N, Bataille R, Mancini C, et al. Myeloma cells induce imbalance in the osteoprotegerin/osteoprotegerin ligand system in the human bone marrow environment. Blood 2001;98:3527-33

114 Croucher PI, Shipman CM, Lippitt J, et al. Osteoprotegerin inhibits the development of osteolytic bone disease in multiple myeloma. Blood 2001;98:3534-40.

115 Hazlehurst LA, Damiano JS, Buyuksal I, et al. Adhesion to fibronectin via $\beta 1$ integrins regulates $\mathrm{p} 27^{\mathrm{kipl}}$ levels and contributes to cell adhesion mediated drug resistance (CAM-DR). Oncogene 2000; 19:4319-27.

116 Rettig MB, Ma HJ, Vescio RA, et al. Kaposi's sarcoma-associated herpes virus infection of bone marrow dendritic cells from multiple myeloma patients. Science 1997;276:1851-4.

117 Tarte K, Chang Y, Klein B. Kaposi's sarcoma-associated herpes virus and multiple myeloma: lack of criteria for causality. Blood 1999; 10:3159-63.

118 Smadja NV, Bastard C, Brigaudeau C, et al. Hypodiploidy is a major prognostic factor in multiple myeloma. Blood 2001;98:2229-38.

119 Pourgourides E, Heath C, Melo JV, et al. Specific action of FGFR inhibitors against $t(4 ; 14)$ positive myeloma cells [abstract]. Blood 2001;98(suppl 1):1560.

120 Hideshima T, Richardson P, Chauhan D, et al. The proteasome inhibitor PS-341 inhibits growth, induces apoptosis and overcomes drug resistance in human myeloma cells. Cancer Res 2001;61:3071-6.

121 Mitsiades N, Mitsiades CS, Poulaki V, et al. Biologic sequelae of nuclear factor-kB blockade in multiple myeloma: therapeutic applications. Blood 2002;99:4079-86 